\title{
Doğrulayıcı Faktör Analizi ile Sağlık Sektöründe Hasta Memnuniyeti Ölçümü Üzerine Bir Uygulama
}

\author{
Esra Nur BEKMEZCI, Adnan AKTEPE, Süleyman ERSÖZ \\ Kırıkkale Üniversitesi, Endüstri Mühendisliği Bölümü, Yahşihan, Kırıkkale, Türkiye \\ esra-nurbekmezci@hotmail.com, aaktepe@gmail.com, sersoz40@hotmail.com
}

\begin{abstract}
Özet
Sağlık sektörü, insanın yaşamını devam ettirebilmesi, hayat kalitesini artırabilmesi ve bu kaliteyi korumasında büyük bir öneme sahiptir. Bu bağlamda ülkelerdeki sağlık hizmetleri seviyesi gelişmişlik düzeyinde önemli bir role sahiptir. Hastanelerin hizmet sağladığı hastanın memnuniyet düzeyini artırması ve koruması gerekmektedir. Bu çalışmada bir Tıp Fakültesi Hastanesinde hizmet alan 200 hastanın memnuniyet ölçümü gerçekleştirilmiştir. Araştırmada veri toplamak için anket yöntemi kullanılmıştır. Memnuniyet dereceleri 5'li Likert tipi anket soruları ile ölçülmüştür. Ankette toplam 28 adet ölçüm değişkeni yer almaktadır. Çalışmada geliştirilen modelde İlgi, İletişim, Güvenilirlik, Sıra Bekleme, Fiziksel Özellik, Hijyen, Genel Memnuniyet ve Bağlllık gizli değişkenleri yer almaktadır. Elde edilen veriler Doğrulayıcı Faktör Analizi yöntemi ile analiz edilmiş olup, sonuçlar tartışılmıştır.
\end{abstract}

Anahtar kelimeler: Doğrulayıcı Faktör Analizi, Hizmet Kalitesi, Müşteri Memnuniyeti, Sağlık Sektörü.

\section{An Application on Measuring Patient Satisfaction in Healthcare Sector with Confirmatory Factor Analysis}

\begin{abstract}
The health sector has a great importance in sustaining human life, increasing the quality of life and maintaining this quality. In this context, the level of health services in the countries have an important role at the level of development. Hospitals need to increase and protect the satisfaction level of the patients they serve. In this study, satisfaction measurement of 200 patients who received service in a Faculty of Medicine Hospital was performed. In the research, survey method was used to collect data. Satisfaction levels were measured with 5 likert scale questionnaire. The survey includes 28 measurement variables in total. The model developed in the study includes Interest, Communication, Reliability, Queue Waiting, Physical Property, Hygiene, General Satisfaction and Loyalty hidden variables. The obtained data were analyzed by the Confirmatory Factor Analysis method and the results were discussed.
\end{abstract}

Keywords: Confirmatory Factor Analysis, Service Quality, Customer Satisfaction, Health Sector.

*Sorumlu Yazar: Adres: Kırıkkale Üniversitesi, Endüstri Mühendisliği Bölümü, Yahşihan, Kırıkkale, Türkiye. Email adresi: esra-nurbekmezci@hotmail.com, Tel: +905418355874 


\section{Giriş}

Müşteri memnuniyeti her sektörde önemli bir unsur olduğu gibi sağlık sektörünü de ayakta tutan yine müşterilerdir. Sağlık sektöründe müşteri olarak adlandırılan unsur hastadır. Hastanenin temizliği, yeterli bilgi birikimine sahip uzmanlarının olması, hastalar ile iletişimin iyi olması, hasta mahremiyetine verilen önem memnuniyet ölçümü için kritik noktalar olsa da hastanenin gelişen ve değişen teknolojiye ayak uydurabilmesi de müşsteri memnuniyet ve sadakatinde önemli yer tutmaktadır.

Müşteri Memnuniyeti ile ilgili literatürde farklı araştırma yöntemlerinin ve tekniklerinin kullanıldığı çalışmalar yer almaktadır. Örneğin; Büber ve Başer [1] Ankara'da bulunan vakıf üniversitesi hastanesinde hizmet alan 80 kişiye 5li likert ölçeği ile anket uygulamıştır. Uygulama sonucu katılımcıların hastanenin fiziki koşullarından memnun oldukları görülmüştür. Ancak hastaneye ulaşım kolaylı̆̆ en düşük puan alan faktör olmuştur. Zineldin [2] çalışmasında müşterilerin kümülatif memnuniyet algısını etkileyen faktörleri incelemiş, Mısır ve Ürdün'de bulunan 3 hastane kapsamında hastaların sağlık hizmetlerinin kalitesini benzer veya farklı değerlendirip değerlendirmedikleri sorununu ele almıştır. Aktepe, Ersöz ve Toklu [3]; çalışmalarında etkili iletişim, müşterilere bağll1ık ve değişimin memnuniyet ve bağlılık düzeyini artırmasına ilişkin beyaz eşya sektöründe müşterileri kendi düzeylerine göre 4 ana grupta incelemiş ve sınıflandırma ve yapısal eşitlik modeli yöntemlerini kullanmışlardır. Toplam 200 kişiye 15 kriterden oluşan yüz yüze görüşmeler ile anket uygulanmıştır. Topal ve Şahin [4]; çalışma kapsamında müşteri memnuniyeti anketi Simav Devlet Hastanesinden hizmet alan 347 kişiye uygulamışlardır. Çalışmada hastanede hizmet kalitesinin yeterince iyi olmayan yönleri $t$ testi ve Faktör Analizi ile belirlenerek eksiklik ve aksaklıkların giderilmesi yönünde öneriler geliştirilmiştir.

$\mathrm{Bu}$ çalışmada ise bir Tip Fakültesi hastanesinde hasta memnuniyetini oluşturulan boyutlar geliştirilmiştir. Boyutların belirlenmesinde Doğrulayıcı Faktör Analizi yaklaşımı kullanılmıştır. Hastane hizmetleri boyutlar bazında analiz edilmiş ve yorumlanmıştır.

\section{Doğrulayıcı Faktör Analizi}

Doğrulayıcı faktör analizinde kullanılan bazı kavramlar aşağıdaki gibidir $[5,6]$.

Gözlenen değişkenler: Veri toplama sürecinde direkt ölçülebilen ve araştırmacı tarafından verileri toplanan değişkenlerdir.

Gizli (gözlenemeyen) değişken: Gizli değişken ise direkt olarak ölçülemeyen fakat araştırmalarda sonuca ulaşabilmek için tanımlanması gereken yapılardır [5]. Gizli değişkenler doğrudan gözlenemediği için doğrudan ölçülemez. Bu nedenle gözlenen değişken aracılığıyla ölçülür $[5,6,7]$.

LISREL 8.80 istatistiksel paket programı [8] yardımıyla doğrulayıcı faktör analizi sonuçlarını literatürde kabul görmüş bazı değerler aracılı̆̆ıyla test edilmesi gerekmektedir. Bunun için ölçütlerin belirli değer aralı̆̆ında olması gerekmektedir [9]. Bu değerlerden bazıları şu şekildedir: 
Ki kare/sd $\leq 3$ (Büyük örneklemler için iyi uyum); p değeri < 0,05; RMSEA (Root Mean Square Error of Approximation) $\leq 0,08$; GFI (Goodness of Fit Index) $=0,80-0,89$ aralı̆ 1 inda (Kabul edilebilir uyum), CFI (Comparative Fit Index) $>=0,90$; NFI (Normed Fit Index) $>=0,90$ (İyi uyum).

Ki-Kare Uyum Testi: Ki-Kare Uyum Testi uygunluk indeksleri içinde en çok kullanılan ve başlangiç olarak sayılabilecek bir testtir. Gözlem değişkenleri ile tasarlanan modele ait kovaryans yapısında ortaya çıkan modelin farklılığını test etmektedir. Ki-kare testinin sonucunun $3^{\prime}$ ten küçük olması modelin uyumlu olduğunu göstermektedir [10].

RMSEA (Tahmin hataları karelerinin ortalamasının karekökü): Model uyum indeksleri içerisinde en çok kullanılan diğer bir yaklaşımdır Modelin kabul edilebilmesi için RMSEA'nın 01 arasında değer alması gerekmektedir. Eğer değer 0.08 'den küçük ise yeterli uyum, 0.05 veya daha küçük bir değer ise mükemmel uyum olduğunu, 0.10 ve üzerindeki değerlerin ise modelin zayıf olduğunu göstermektedir [10].

Normlaştırılmış Uyum İndeksi (NFI): Ki-kare değerinin bağımsız modelin ki-kare değerine bölünmesiyle NFI değeri elde edilmektedir. NFI 0 ile 1 arası bir değer almakta ve indeksin alacağı 0,90 dan büyük değerler kabul edilebilir anlamına gelmektedir [10].

İyilik Uyum İndeksi (GFI): Varyans ve kovaryansın nispi miktarıyla ilgili bir ölçüyü ifade etmektedir. 0 ile 1 arasında değer almakla birlikte 0,80 ' den büyük değerler kabul edilebilir değerler olarak bilinirken 0,90 ve üzeri değerler modelin iyi uyumlu olduğunu göstermektedir [9].

\section{Uygulama}

LISREL'de analiz aşamasına geçmeden önce elde edilen veri setinin düzgün bir şekilde hazırlanmış olması analiz aşamasını kolaylaştırmaktadır. Bu nedenle SPSS [11] yazılımı ile değişkenler sırasıyla tanıtılmalıdır. Tanımlama işlemi yapıldıktan sonra veri seti LISREL [8] programına aktarılır. Daha sonra LISREL ile model geliştirilir. Ölçüm modeli uyum istatistikleri kabul edilebilir, iyi veya mükemmel uyum değerlerine sahip olması gerekmektedir.

Uygulamamızda 8 gizli ve 28 ölçüm değişkeni bulunmaktadır. Her ölçüm değişkenine ait 200 veri bulunmaktadır. Ölçüm değişkenleri sırasıyla kısaca ILGI1, ILGI2, ILGI3, IL1, IL2, IL3, IL4, GVN1, GVN2, GVN3,GVN4, FO1, FO2, FO3, FO4, FO5, FO6, HJ1, HJ2, HJ3, HJ4, SB1, SB2, SB3, GM1, GM2, BG1, BG2 olarak adlandırılmıştır. Gizli değişkenler ise "ilgi”, "iletisim”, "guven", "fizoz", "hijyen", "sirabek", "genelmem", "baglilik" olarak adlandırılmıştır. İlgi boyutundaki ölçüm değişkenleri: ILGI1, ILGI2, ILGI3; İletişim boyutundaki ölçüm değişkenleri: IL1, IL2, IL3, IL4; Güven boyutundaki ölçüm değişkenleri: GVN1, GVN2, GVN3, GVN4; Fiziksel Özellikler boyutundaki ölçüm değişkenleri: FO1, FO2, FO3, FO4, FO5, FO6; Hijyen boyutunda yer alan ölçüm değişkenleri: HJ1, HJ2, HJ3, HJ4; Sıra Bekleme boyutundaki ölçüm değişkenleri: SB1, SB2, SB3; Genel Memnuniyet boyutundaki ölçüm değişkenleri: GM1, GM2 ve Bağlılık boyutundaki ölçüm değişkenleri BG1, BG2 olarak tanımlanmıştır. Tanımlama işlemi 
her gizli değişkenden ölçüm değişkenine tek yönlü ok çizilerek gerçekleştirilmiştir. Her bir ölçüm değişkeni için bu işlem yapıldıktan sonra çizilen "path diagramı" analiz için hazır hale gelmiştir. Analiz sonucunda elde edilen sonuç Şekil 1'de gösterilmektedir.

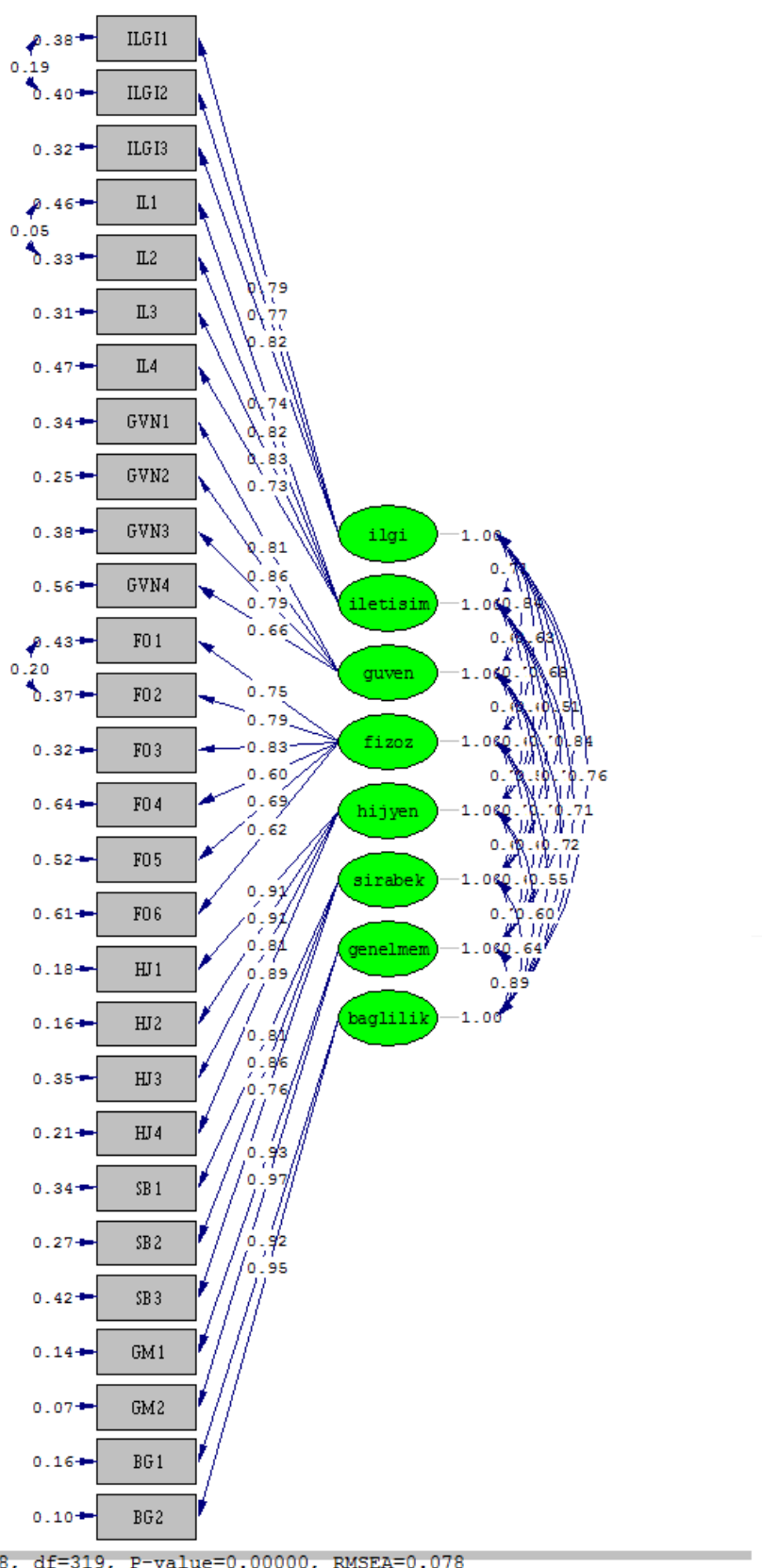

Chi-Square $=707.48, \mathrm{df}=319, \mathrm{P}$-value $=0.00000, \mathrm{RMSEA}=0.078$

Şekil 1: Doğrulayıcı Faktör Analizi Modeli (Standart Çözüm)

Tasarlanan modelin doğrulayıcı faktör analizi sonuçları incelendiğinde modeldeki ölçüm değişkenlerinin (soruların), boyutlara uygun olduğu görülmektedir. Doğrulayıcı faktör analizi uyum istatistikleri Tablo 1'de gösterilmektedir. 
Tablo 1: Uyum İstatistikleri

\begin{tabular}{lcl}
\hline Ölçüt & Sonuç & İstatistiksel Uyum \\
\hline Ki-kare/df & 2,22 & İyi Uyum \\
\hline RMSEA & 0,078 & İyi Uyum \\
\hline NFI & 0,96 & Mükemmel Uyum \\
\hline NNFI & 0,97 & Mükemmel Uyum \\
\hline GFI & 0,80 & Kabul Edilebilir Uyum \\
\hline CFI & 0,98 & Mükemmel Uyum \\
\hline
\end{tabular}

RMSEA 0 ile 1 arasında değer almaktadır. 0,08'e kadar olan değerler modelin kabul edilebilir olduğunu gösterir. Ki-kare/df oranı $(2,22), 3$ değerinden küçük olması da modelin uyumlu olduğunu göstermektedir.

\section{SONUÇ ve DEĞERLENDİRME}

Bu çalışmada bir Tıp Fakültesi hastanesinden hizmet alan hastaların aldıkları hizmetlerden memnun olup olmadıkları, memnun değillerse bu düşüncelerinde hangi kriterin/kriterlerin etkili olduğunu belirlemek amaçlanmıştır.

Boyut bazında yapılan puan ortalama sonucuna göre boyutların 5 üzerinden puan sıralaması şu şekildedir: Güvenilirlik: 3,54; İlgi: 3,28; Genel Memnuniyet: 3,13; Fiziksel Özellik: 3,11; Hijyen: 3,10; Bağlılık: 3,10; İletişim: 3,05 ve Sıra Bekleme: 2,82. Yapılan sıralamaya göre hastaneye gelen hastaların memnuniyet seviyesinin en yüksek olduğu boyut güvenilirlik, en az memnun oldukları boyut ise Sıra Bekleme olarak tespit edilmiştir.

Uygulama yapılan kurumda hizmet kalitesini iyileştirmek için geliştirilen önerilerden bazıları şu şekildedir: hastaların bekleme sürelerini minimize etmek için randevu sisteminin uygulanması, görevlilerin hastalar ile iletişim düzeyinin artırılması ve hastanede havalandırmanın daha iyi bir düzeyde sağlanması. 


\section{Kaynakça}

[1] Büber R., Başer H., Sağlık İşletmelerinde Müşteri Memnuniyeti: Vakıf Üniversitesi Hastanesinde Bir Uygulama, 2012.

[2] Zineldin M., The quality of health care and patient satisfaction: An exploratory investigation of the 5Qs model at some Egyptian and Jordanian medical clinics, 2006.

[3] Aktepe A., Ersöz S., Toklu B, Customer satisfaction and loyalty analysis with classification algorithms and Structural Equation Modeling, Computers and Industrial Engineering, 86, 95-106, 2015.

[4] Topal B., Şahin H., Sağlık Sektöründe Müssteri Memnuniyetinin Ölçümü: Simav Devlet Hastanesi Örneği, 2017

[5] Byrne B. M., Multivariate applications series, Structural equation modeling with AMOS: Basic concepts, applications, and programming, 2010.

[6] Altun S., Elektrik Dağıtım Hizmetleri Sunan Bir İşletmede Müşteri Memnuniyetini Etkileyen Faktörlerin Yapısal Eşitlik Modellemesi İle Belirlenmesi, Yüksek Lisans Tezi, 2019.

[7] Ergül S., Türkiye'de Elektronik Pazaryerlerinde Hizmet Kalitesi, Güven ve Satın alma Niyeti Arasındaki İlişki: Yapısal Eşitlik Modeli Uygulaması, 2017.

[8] Joreskog, K. G., Sorbom, D., LISREL 8.80 for windows (computer software), Lincolnwood, IL: Scientific Software International, Inc.

[9] Berberoğlu E., Uygun S., Çevre Farkındalığı-Çevre Tutumu Arasındaki İlişkinin Yapısal Eşitlik Modeli İle Sinanmas1, 2012.

[10] Meydan H. C., Şeşen H., Yapısal Eşitlik Modellemesi AMOS Uygulamaları, Detay Yayıncılık, Ankara, 2011.

[11] SPSS, IBM SPSS Statistics, https://www.ibm.com/tr-tr/products/spss-statistics. 